\title{
Medievalista
}

Online

$29 \mid 2021$

Número 29

Quatro olhares sobre um historiador

\section{Peter Linehan, in memoriam}

Quatro olhares sobre um historiador

Peter Linehan, in memoriam: Four Portraits of an Historian

André Evangelista Marques, Maria João Branco, Mário Farelo e André Vitória

\section{OpenEdition \\ Journals}

\section{Edição electrónica}

URL: https://journals.openedition.org/medievalista/4032

DOI: 10.4000/medievalista.4032

ISSN: $1646-740 \mathrm{X}$

\section{Editora}

Instituto de Estudos Medievais - FCSH-UNL

\section{Edição impressa}

Paginação: 13-48

\section{Refêrencia eletrónica}

André Evangelista Marques, Maria João Branco, Mário Farelo e André Vitória, «Peter Linehan, in memoriam», Medievalista [Online], 29 | 2021, posto online no dia 01 janeiro 2021, consultado o 24 julho 2021. URL: http://journals.openedition.org/medievalista/4032 ; DOl: https://doi.org/10.4000/ medievalista.4032

Este documento foi criado de forma automática no dia 24 julho 2021

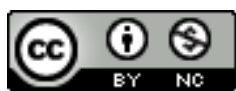

Mediavalista está licenciado com uma Licença Creative Commons - Atribuição-NãoComercial 4.0 Internacional. 


\title{
Quatro olhares sobre um historiador \\ Peter Linehan, in memoriam
}

\author{
Quatro olhares sobre um historiador
}

Peter Linehan, in memoriam: Four Portraits of an Historian

André Evangelista Marques, Maria João Branco, Mário Farelo e André Vitória

\section{NOTA DO EDITOR}

Data recepção do artigo / Received for publication: 3 de Dezembro de 2020

1 Peter Linehan deixou-nos no dia 9 de Julho de 2020. O seu trabalho sobre Portugal tem uma relevância incontestável e será por muito tempo uma referência maior para quem estuda os temas sobre os quais ele escreveu e ensinou. Tinha muitos amigos e colegas em Portugal, a quem inclusivamente dedicou um dos seus livros. Era, para além disso, membro do Conselho Editorial da revista Medievalista. Estas razões pareceram-nos mais do que suficientes para escrever, precisamente na Medievalista, um texto em sua memória, que pudesse dar ao mesmo tempo uma visão sobre o seu trabalho como historiador e a sua personalidade como académico.

Pareceu-nos assim lógico juntar os quatro elementos do IEM que mais de perto lidaram com ele e escrevermos, cada um de nós, um texto que reflectisse a nossa imagem particular do historiador e do homem que conhecemos e com quem privámos. Deste esforço resultaram quatro textos muito distintos que, não obstante, apresentam uma notória consonância. Decidimos por isso mantê-los individualizados, por nos parecer que isso enriqueceria o retrato que queríamos traçar e faria mais justiça ao complexo historiador que era Peter Linehan.

\section{Peter Linehan, decanus ille}

4 1. Agosto de 2007. A cena passou-se durante a segunda de várias estadias em Cambridge que devo à hospitalidade de Peter Linehan. Recém-inscrito no doutoramento, e com a avidez de quem ia descobrindo um oceano de bibliografia, aproveitei um dos nossos 
encontros para lhe pedir indicações sobre livrarias e alfarrabistas ingleses. Afundado num sofá grande e rodeado por alguns milhares de livros nas paredes, mais largas dezenas espalhadas por sofás, mesas, cadeiras e pelo chão do seu gabinete, respondeume: "Livros?! Tenho demasiados. Só quero que eles desapareçam.", e mudou de assunto․ Já não consigo reconstituir o resto da conversa, mas lembro-me de ter saído desconcertado. Pouco depois, quando me sentei ao computador na biblioteca, tinha uma pequena lista comentada de livrarias e alfarrabistas no email.

5 Nunca esqueci este episódio. Pelo que ele diz da minha ingenuidade: tendo a possibilidade de explorar as bibliotecas de Cambridge, estava preocupado em açambarcar o maior número possível de livros para trazer para casa. Mas sobretudo pelo que ele revela da personalidade de Peter Linehan, que eu só viria a conhecer melhor mais tarde. Olhando para trás, vejo na sua resposta a sagacidade com que rapidamente percebia pessoas e comportamentos, fossem eles de jovens estudantes postos à sua frente ou de gente cuja voz só lhe chegou em textos medievais. Vejo também a atitude desconcertante que cultivava, tanto na escrita como no trato pessoal, e que prontamente transformava em sarcasmo quando confrontado com algum dos seus ódios de estimação ou com qualquer forma de mediocridade intelectual. Vejo ainda o gosto pelos jogos de ocultação e revelação, fonte do entusiasmo com que sussurrava estórias dos fantasmas que rondavam o seu gabinete no St John's College, ou relatava as suspeitas de espionagem em que se viu envolvido no primeiro périplo que fez pelos arquivos eclesiásticos espanhóis, nos anos 60 . Vejo, por fim, a generosidade com que franqueou as portas do St John's e da sua universidade a tantos académicos de Espanha e Portugal ${ }^{2}$.

6 2. Não posso deixar de registar aqui a minha dívida de gratidão, que vale como um exemplo entre muitos. Em 2005, tendo participado na V Semana de Estudos Medievais organizada na Faculdade de Letras do Porto, Peter Linehan convidou-nos, a um grupo de alunos de pós-graduação em que estavam incluídos André Vitória, Flávio Miranda, Joana Sequeira, Maria João Silva e eu, a fazer uma breve estância em Cambridge. Aí passámos, os cinco, algumas semanas do Verão de 2006; e aí regressei para sucessivos períodos estivais até 2009 e por todo o ano letivo de 2010-2011. Durante estes anos, que abrangem o final da escrita da minha dissertação de mestrado e a preparação da de doutoramento, fiquei a dever-lhe a grande simpatia com que sempre tratou da logística do meu alojamento e com que me permitiu aceder à incomparável Biblioteca da Universidade de Cambridge, sem a qual a minha formação como historiador teria resultado bem mais pobre. Devo-lhe também uma atenção discreta mas vigilante ao meu trabalho, própria de quem passou décadas a acompanhar alunos no quadro do sistema tutorial de Oxbridge, e uma série de pequenos favores que dão bem a medida da atenção que dedicava aos seus hóspedes, desde a compra de livros com o seu desconto de autor à intermediação do contacto com outros académicos ingleses. Rapidamente se tornou claro que o meu interesse pela Alta Idade Média, e sobretudo a minha opção pelo estudo do espaço, que lhe provocava, creio, o mais absoluto tédio, limitavam os pontos de conversa entre nós. Mas a sua agudeza (wit é a palavra certa) e imaginação fizeram das conversas que fomos tendo ao longo desses anos uma lição muito viva sobre as subtilezas da análise histórica e a importância do discurso no trabalho do historiador.

7 3. 0 coração da sua obra, ancorado numa tese doutoral apresentada em Cambridge em 1969 e logo transformada em livro (1971), está dedicado ao estudo da Igreja ibérica 
entre os séculos XII e XIV, não apenas como instituição que se constrói numa tensão entre as monarquias ibéricas e Roma, mas também como corpo social e político com uma acção própria (mas não unívoca) e um papel relevante na produção de cultura jurídica e de memória histórica ${ }^{3}$. Assim se percebe a extensão do trabalho de Peter Linehan à história do papado e do direito canónico, por um lado, e à história do poder régio e da cultura letrada, por outro. A estes temas correspondem vários dos seus livros (1971, 1993, 1997, [2003], 2004, 2019), os importantes guias/edições de fontes pontifícias que produziu (2013, no prelo) e muitos dos artigos reunidos em quatro colectâneas (1983, 1992, 2002, 2012), para além de outros textos que permanecem avulsos. Sendo menos competente do que os autores que me acompanham nesta homenagem da Medievalista para avaliar o contributo de Peter Linehan em cada uma destas áreas, opto por chamar aqui a atenção para alguns aspectos mais oficinais que permeiam o conjunto da obra e que acabaram por marcar em grande medida a sua originalidade.

4. O primeiro destes aspectos decorre do interesse de Peter Linehan pelos processos de construção historiográfica da memória e pelos seus usos, aquilo que definiu como "the invention of the past: the manner in which, for reasons which have seemed good to them, (...) men have sought to appropriate and recolonize the past" ${ }^{\text {. }} \mathrm{O}$ seu vasto conhecimento da historiografia espanhola e uma intuição apurada permitiram-lhe perceber, ao longo dos anos 1960 e 1970, a crise de um paradigma historiográfico assente no binómio nacionalismo/catolicismo e a sua substituição por outro mais europeísta, mas também mais regionalista, que foi dominante até há pouco tempo. A uma visão em que os conceitos de Reconquista e Repovoamento serviam para legitimar um discurso identitário e político de cariz centralista (e castelhanista), sucedeu outra empenhada em legitimar a Espanha autonómica e aberta à Europa, articulada em torno a uma noção demasiado vaga de "feudalismo" 5 . A estas questões dedicou Peter Linehan vários artigos a partir de 1982, quando o medievalismo - entendido na acepção de estudo dos usos e representações da Idade Média - dava ainda os primeiros passos na Europa e nos Estados Unidos (1982, 1992 [I e II], 1996, 2012).

9 Mas a sua grande originalidade está em ter percebido e investigado a fundo as ligações entre os usos da Idade Média feitos pelos historiadores modernos e contemporâneos e os usos que os próprios cronistas medievais fizeram do seu passado. Naquele que é provavelmente o seu opus magnum, History and the Historians of Medieval Spain (1993), traça uma panorâmica da história da Península Ibérica entre os séculos VI e os meados do XIV - centrada no espaço castelhano-leonês - na qual se entrelaçam três planos de análise: (i) a narrativa histórica propriamente dita, ancorada nas questões políticas e eclesiásticas que o autor vinha a estudar há mais de duas décadas a partir da documentação régia, pontifícia, episcopal e monástica; (ii) a análise detalhada das sucessivas crónicas e cronistas que foram construindo a memória do reino de LeãoCastela e forjando diferentes visões do passado, não raro contraditórias entre si e usadas como arma política; e (iii) a ligação permanente entre os dois planos anteriores e a obra dos eruditos e historiadores espanhóis que retrabalharam e usaram essas memórias nos séculos pós-medievais. Com mestria narrativa e rara capacidade analítica, Peter Linehan vai guiando o leitor por um longo périplo que deve ser lido simultaneamente como uma panorâmica (certamente parcial) da história peninsular medieval, uma síntese (hoje ultrapassada em muitas questões de pormenor mas não na visão de conjunto) da historiografia medieval castelhano-leonesa e um ensaio de história da historiografia que, estando longe de se limitar ao século XX, procurava claramente mapear a herança que pesava sobre o medievalismo espanhol nos anos 90 . A 
escrita deste livro obrigou o autor a trabalhar, na prática, em três campos distintos. Mas a opção final por tecer os vários fios numa trama só permitiu-lhe mostrar como os autores medievais criaram um conjunto de topoi que persistiram longamente na historiografia espanhola e como a Idade Média foi usada por sucessivas gerações de historiadores para legitimar as visões do presente que tinham a propor aos seus contemporâneos.

10 A obra teve uma recepção tímida em Espanha, desde logo pelas dificuldades que a sua leitura colocava a um público pouco familiarizado com o inglês sofisticado do autor, mas também pelo desconforto que a crítica por vezes mordaz ao medievalismo espanhol contemporâneo motivou, com historiadores destacados a denunciarem-na como simplista em alguns aspectos, sem contudo negarem o valor do livro ${ }^{6}$. 0 facto de Portugal e a construção de uma mitologia nacional portuguesa estarem praticamente ausentes de uma obra essencialmente preocupada com os reinos de Astúrias-LeãoCastela, e com a monarquia espanhola que lhe sucedeu, explica a relativa discrição com que o livro foi recebido também no nosso país, com excepções que só confirmam a regra $^{7}$. Mas a verdade é que History and the Historians aguentou bem a passagem do tempo e, quase 30 anos depois do seu aparecimento, transformou-se num clássico, e não apenas para os estudiosos da Península Ibérica medieval. A atenção à "ever shifting relationship of past and presente over time" ${ }^{\prime 8}$ faz deste livro um precursor do muito trabalho recente em torno das "origens medievais" do nacionalismo contemporâneo e das "origens modernas" da Idade Média", perspectivas que Peter Linehan soube combinar como poucos até hoje. $\mathrm{O}$ historiador a quem a especulação teórica pósmoderna provocava uma clara repulsa ${ }^{10}$ foi afinal um dos medievalistas europeus que melhor percebeu a importância da análise dos textos como objectos que respondem a contextos de produção específicos e cuja capacidade agente foi reactivada e actualizada em momentos sucessivos. Mais do que tema de um livro, a contaminação entre passado e presente foi transformada por Peter Linehan numa espécie de regra de método que permeou cada vez mais o seu trabalho.

115.0 interesse pelo indivíduo e pela forma como a sua acção se concretiza na moldura de cada tempo está na raiz do segundo aspecto que quero sublinhar na obra de Peter Linehan: o cultivo exímio da micro-história e da biografia, não só como formas de escrever história mas sobretudo como método de análise. Foi na descrição minuciosa das personagens em situação, procurando deslindar os mais ínfimos nexos entre a acção individual e o contexto epocal, e nunca descurando o posicionamento e a percepção das próprias personagens, numa espécie de "thick description" (Clifford Geertz) em que o historiador e os textos se substituem ao etnógrafo e ao trabalho de campo, que Peter Linehan encontrou o seu modo de aceder à realidade que lhe interessava estudar, essencialmente a acção política e simbólica nas esferas eclesiástica e régia. Dominando um vastíssimo corpus de fontes documentais e narrativas, Peter Linehan preferiu sempre explorar textos ou conjuntos de textos específicos, referindose aos grandes problemas a partir de descrições densas de casos concretos, do que voar sobre largas séries documentais para traçar panorâmicas descarnadas assentes na generalização, seja ela de base indutiva ou dedutiva, donde a sua reserva quanto à história quantitativa e a recusa em escrever as grandes sínteses que mais do que uma vez lhe foram propostas. À abstracção, que via como possível fonte de erro, simplificação e anacronismo, antepôs sempre a distinção. 

uma forma ou de outra, mas em especial na sua aclamada incursão pelas aventuras de uma comunidade de monjas dominicanas em luta contra o respectivo bispo diocesano na Zamora do século XIII. The Ladies of Zamora (1997), que viria a ser rapidamente traduzido para francês (1998) e castelhano (2000), e mais tarde para português (2009), tornou-se num clássico do género ${ }^{11}$. Partindo da exploração detalhada do texto de um inquérito lançado pelo bispo Suero Pérez ao comportamento moral da comunidade e às suas relações com os frades dominicanos da cidade, Peter Linehan foi capaz de convocar um amplo conjunto de fontes e de personagens (peninsulares e extrapeninsulares) para pintar um fresco muito vivo da religião e da política ibéricas nos finais do século XIII, com todas as suas implicações e extensões europeias. Esta opção por objectos de estudo concretos e situados é também evidente na biografia do arcebispo de Toledo Gonzalo Pérez Gudiel que escreveu em colaboração com Francisco J. Hernández (2004), aproveitando um conjunto extraordinário de fontes. A sensação que fica deste e de outros trabalhos que revelam o fascínio de Peter Linehan pelo indivíduo, pelos meandros da personalidade e pela complexidade do comportamento humano é a de que o autor conhecia intimamente as personagens sobre quem escrevia e, como qualquer bom escritor, foi capaz de lhes dar tal substância, ancorada num trabalho rigoroso com as fontes, que essas personagens não só aparecem inteiras e plausíveis aos olhos do leitor como são capazes de iluminar todo um tempo.

6. Só alguém hábil na utilização quase cubista de determinados ângulos da realidade para evocar o todo, e muito seguro da sua própria leitura da história peninsular, ousaria escrever um livro tão idiossincrático como o volume com que contribuiu para a série A History of Spain da Blackwell, a que chamou Spain, 1157-1300: A Partible Inheritance (2011). Num contraste evidente com a prosa enxuta e a narrativa política escorreita dos capítulos sobre os reinos ibéricos nos séculos XII a XIV que escreveu para a New Cambridge Medieval History (1999, 2000, 2004), o livro da Blackwell recusa o modelo da síntese mais ou menos compreensiva que caracteriza os restantes volumes da série. Ao invés, constrói-se a partir de uma composição de temas, espaços e dramatis personae tidos como especialmente reveladores do período e das especificidades que Peter Linehan reconhecia na realidade ibérica, quando comparada com outras regiões da Europa medieval. Detendo-se sobretudo no século XIII, e em especial no reinado de Afonso X, e adoptando mais uma vez o reino de Leão-Castela como ponto de observação das forças centrífugas que marcam a história peninsular na longa duração e estão na raiz do mito da unidade hispânica, Peter Linehan aponta os holofotes ao exercício do poder político (desde logo régio) e converte-o no fio condutor de um enredo em que não deixa de convocar aspectos "não-narrativos"12, como a ideia de que a Reconquista criou uma "society disorganized by civil war", num quadro de grande carência demográfica e de dificuldades na manutenção das estruturas básicas do povoamento nos territórios conquistados. Viria a utilizar a mesma técnica analítica e narrativa no seu último livro, At the Edge of Reformation (2019), uma "sequela não oficial" do livro da Blackwell - como notou um recenseador recente ${ }^{13}$ - que cobre a primeira metade do século XIV.

7. Numa história tão marcadamente narrativa e autoral, o texto é chamado a desempenhar um papel central, que se manifesta tanto na construção do enredo como no trabalho estilístico. Chego assim ao último aspecto da obra de Peter Linehan que procuro aqui evocar: a utilização do texto como um espaço que torna possível, e em que

Medievalista, 29 | 2021 
convivem, a recriação do passado e a intervenção do próprio historiador. Profundo conhecedor de uma enorme quantidade e variedade de textos medievais, Peter Linehan tinha bem consciência das limitações que as fontes escritas colocam ao trabalho dos historiadores, fruto dos constrangimentos da sua produção e das circunstâncias que ditaram a transmissão de uns textos em detrimento de outros. Leitor ávido de ficção, é natural que tivesse moldado o seu papel de historiador a partir do posicionamento de um narrador que, não sendo omnisciente, também não prescinde de ser um intérprete qualificado da história que narra. Quando Juan Miguel Valero lhe perguntou quais as suas principais influências historiográficas, Peter Linehan respondeu, subversivamente, que Charles Dickens e Thomas Hardy terão pesado mais do que qualquer historiador, o primeiro pelo que as suas personagens e caricaturas lhe ensinaram e o segundo por terlhe mostrado o papel da contingência e a importância do inesperado na vida ${ }^{14}$. Percebese assim o uso que Peter Linehan faz de recursos eminentemente literários, como sejam a urdidura cuidada do enredo, a caracterização subtil das personagens e a evocação detalhada de ambientes, para colmatar os muitos espaços em branco de uma realidade passada, que as fontes reflectem de forma bastante fragmentária e esbatida. Percebe-se também a liberdade que cultivou em matéria de estilo. Para alguém que via a história como sendo "acima de tudo comunicação", o estilo é necessariamente um instrumento retórico, uma ferramenta para captar a atenção do leitor ${ }^{15}$. Mas no caso de Peter Linehan é mais do que isso: a adjectivação certeira, um sentido de humor que não hesita em fazer-se ironia, quando não sarcasmo, a paráfrase em que a interpretação se sobrepõe à mera glosa das fontes, são tudo recursos que servem a afirmação da voz do historiador/narrador sobre a matéria narrada.

8. Brian Catlos viu no último livro de Peter Linehan um autor tão embrenhado na sua história que acaba por se alhear do leitor ${ }^{16}$. A crítica pode parecer justa à superfície, mas falha o essencial. Peter Linehan nunca deixou de ter em mente os seus leitores. Só não escrevia para um leitor-tipo, como os estudantes universitários que Catlos diz serem hoje incapazes de ler com proveito At the Edge of Reformation, ou os públicos alargados que a propaganda editorial canonizou. $\mathrm{O}$ seu leitor era culto, imaginativo, com sentido de humor e sobretudo questionador; um leitor construído mais e mais à imagem do próprio autor. "Como la poesía o el estreñimiento, la historia debe salir del sistema del historiador", disse ${ }^{17}$. A observação deste preceito levou Peter Linehan a construir uma obra marcada pelos seus traços de personalidade mas também, nunca é de mais sublinhá-lo, por extraordinários recursos intelectuais: o domínio de um volume impressionante de fontes, que nunca deixou de ir alargando até ao final da vida, um conhecimento muito vasto - e sobretudo crítico - da bibliografia nas principais línguas europeias, uma capacidade analítica invulgar, que tanto lhe permitia atentar no mais ínfimo detalhe como identificar os traços dominantes de uma personagem ou as grandes tendências de um tempo, um talento evidente para a escrita. Peter Linehan dividia os historiadores entre os que gostam de ler e os que gostam de escrever. Presumo que reconhecesse aos primeiros uma maior necessidade de ouvir o passado e aos segundos uma maior urgência de o dizer. Nunca percebi bem em que grupo é que se incluía. Mas talvez esta dicotomia lhe servisse sobretudo para ocultar a genialidade de quem reunia em si capacidades que poucos historiadores reúnem, e que ainda menos conseguem transformar num corpo de trabalho monumental, construído de forma persistente, consistente e consequente ao longo de uma vida. 

às caves do vinho do Porto, as comunicações apressadas e as longas sessões soleníssimas. Foi com agrado que regressou ao Porto, mais uma vez para outro Congresso, em 2005, para se encontrar com um mundo académico muito diferente, e sobretudo para conhecer um grupo de jovens e promissores investigadores - excelentes em qualquer parte do mundo, gostava de sublinhar - com quem estabeleceu de imediato uma enorme empatia e com quem viria a conviver de perto em Cambridge, onde todos foram fazer estadias maiores ou menores de investigação, explorando os 
recursos e as bibliotecas dessa universidade, bem como usufruindo da generosidade do conhecimento enciclopédico, da experiência e extraordinária memória do Peter, da sua própria biblioteca pessoal e da biblioteca do "seu" St John's College, aberta 24 horas por dia.

Também eu, como dezenas de jovens e menos jovens académicos ibéricos, beneficiara de idêntica generosidade, em 1996, quando, na sequência de mais um congresso, em Birmingham, aceitei o seu desafio, em início de levantamento documental para a minha tese de doutoramento, para fazer uma estadia em Cambridge. Aí tive acesso aos microfilmes da documentação do Vaticano (na era anterior à digitalização, a biblioteca do St John's tinha microfilmado toda a documentação da chancelaria pontifícia, que se podia ler sem restrições) e pude beneficiar do paraíso que é, para qualquer um, uma biblioteca de acesso aberto como a Biblioteca da Universidade. Pude ainda contactar com um conjunto de académicos hispânicos a quem o Peter também convidara para passarem temporadas em Cambridge, a quem ajudava a encontrar alojamento, para quem arranjava privilégios de acesso aos recursos de investigação do colégio e Universidade e a quem ainda convidava para sua casa, levava a visitar pubs, casas de chá e catedrais na vizinhança, para além de os receber no seu escritório para infindáveis e profícuas tertúlias no meio dos seus inumeráveis livros, fotocópias, separatas e microfilmes, que gostava de procurar para dividir e discutir connosco. Era um trabalhador incansável, lia compulsivamente, livros de história e ficção, poesia e prosa, que integrava na sua escrita da história. Era também um melómano muito culto, partilhando com os seus convidados todo esse gosto pelas coisas do espírito com grande sensibilidade e generosidade.

Tinha conhecido o Peter Linehan ainda noutro congresso, em Toledo, em 1989, quando se comemoravam os 1400 anos da conversão de Recaredo ao catolicismo, no III Concílio de Toledo, onde ele estava com o seu amigo de sempre, Francisco Hernández, e onde ambos quiseram falar comigo depois da minha comunicação, pediram para ver os documentos que eu mencionara, confirmaram as minhas referências e leram-nos num cafezinho meio rançoso de uma viela toledana, discutiram as minhas ideias comigo naquilo que parecia uma demonstração exemplar e imerecida de espírito académico ideal.

Num congresso sobre um tema tão relevante para a construção de uma identidade hispânica centrada na irreal ideia de grandiosidade em torno da conversão a um catolicismo alegadamente unificador, tão característica dos sectores mais conservadores e eclesiásticos da então historiografia hispânica, que decorreu no lugar talvez mais simbolicamente marcante para essa mesma construção, Peter Linehan apresentou uma comunicação que pretendia verificar qual fora o impacto do III Concílio de Toledo na historiografia coeva e na restante historiografia medieval, deitando por terra, em menos de meia hora e com argumentos de peso, a ideia da magna relevância de Recaredo, dos visigodos e do III Concílio de Toledo para essa mesma identidade, durante a Idade Média. Não esteve sozinho nessa empresa, nesse extraordinário congresso onde se digladiaram duas concepções historiográficas e duas mundivisões radicalmente opostas, mas impressionava a clareza, o rigor, a concisão e a argumentação, para além da coragem de verbalizar uma realidade tão a contracorrente, num ambiente tão hostil a tal mensagem. Esta aparente irreverência, que mais não era do que a aplicação de uma crítica documental implacável e rigorosa a uma problemática 
que se procurava desvestir da sua secular mitificação, revelou-me desde logo o tipo de académico que o Peter Linehan era.

Não sabia então, mas apercebi-me mais tarde, que Linehan estava em pleno processo de gestação da sua magna obra History and the Historians of Medieval Spain, que veria a luz do dia em 1993, e que teve muito menor recepção e ainda menor impacto do que realmente merecia, então como agora. Nele, como o texto de André Marques nesta mesma homenagem demonstra à saciedade, é todo um vintage Linehan que se pode encontrar a cada página. Um académico maduro, crítico, original e intuitivo, que trabalha a historiografia como uma fonte a desconstruir tendo em vista o triplo filtro dos homens que a constroem, dos contextos em que são produzidos e aqueles que eles procuram retratar, combinando-o com a análise dos artifícios retóricos e das manipulações políticas usadas por quem compõe os textos e por quem os utiliza, modifica, reutiliza e repensa.

Combinando a inteligência crítica do autor com o conhecimento profundo que então já tinha dos contextos que analisava, dos meandros da produção historiográfica e da releitura sistemática e extensiva dessa mesma historiografia e das fontes documentais, o resultado é uma obra que nunca encontrou o lugar que merecia em vida do autor, muito embora, passados quase 30 anos sobre a sua edição em inglês, ainda não tenha perdido a pertinência das propostas e das possibilidades que levanta. Um extenso livro que cobre a História, os Historiadores e a Historiografia Hispânica, sobretudo centrado em Leão e Castela do século VI ao século XIV, muito embora com muita informação sobre Portugal, dá-nos a dimensão das suas preocupações e levanta o véu sobre o seu método de trabalho. Percebe-se bem porque, sendo um historiador que trabalhou desde o doutoramento a Igreja hispânica enquanto instituição e os eclesiásticos como actores fundamentais na nessa progressiva e deficiente institucionalização, detestava ser apelidado de historiador da Igreja ou descrito como alguém que se dedicava à História Eclesiástica. Tinha razão, pois a obra que nos deixa vai muito para além dessas redutoras classificações. A sua obra dispersa-se por diversos temas que vai estudando, ao sabor do que a obra anterior lhe sugeria e do que a sua aturada e exaustiva pesquisa documental lhe ia permitindo estudar. O seu labor historiográfico deteve-se na Igreja hispânica, obviamente, mas sobretudo nos homens da Igreja hispânica, quer como grupo, quer como indivíduos, nas suas múltiplas e por vezes até contraditórias facetas. É através deles que ele chega à história política, à história da relação entre o poder régio e a Igreja, e depois ao estudo do poder régio em tantas outras vertentes, à escrita do passado e suas manipulações, à cultura jurídica e aos canonistas hispânicos, aos conflitos jurídicos e à diplomática, ao retraçar de percursos individuais como óbvios representantes de conjunturas muito mais alargadas, processos mais globais que se revelam pelos traços que nos deixam, na livraria de um arcebispo, nos rascunhos de uma carta escritos e reescritos por uma mente torturada pelo medo de ter a sua posição em risco, pela agência dos cardeais hispânicos em Roma, pelas ambições e dúvidas de um bispo zamorano, pelas grandes questões que se colocam à cúria pontifícia num Ocidente em crise ou por um escândalo num convento de dominicanas com repercussões tais que abalaria todo um sistema de hierarquias e poderes que iriam da Península Ibérica a Roma. 0 grupo e o indivíduo funcionam na sua historiografia quase sempre como leitmotivs, como abordagens "micro", densas de significados e significantes, fundamentais para a compreensão dos signos de um universo muito mais "macro". 
30 A década de 90, que assistiu à publicação de History and Historians of Medieval Spain (1993) e The Ladies of Zamora (1997), dois livros que deixariam uma marca indelével na historiografia actual, assitiu também a uma explosão de artigos sobre os temas que o iriam ocupar de aí em diante: a historiografia hispânica do século XIII e seus autores, Lucas de Tuy, Rodrigo Jiménez de Rada e Juan de Soria, que deixou o anonimato, a historiografia alfonsina, a cultura jurídica peninsular e as relações com a cúria pontifícia, os meandros políticos, sociais, simbólicos e rituais da construção da soberania régia nos séculos XII a XIV e seu relacionamento com a "Igreja", e as vidas e percursos de eclesiásticos, legados pontifícios, cardeais, arcebispos, bispos e cónegos, ou as peripécias jurídicas de comunidades monásticas, como as monjas de Lorvão.

O final da década de 90 marca também a inclusão nos seus interesses académicos da realidade portuguesa, que uma documentação inexplorada lhe possibilitaria.

Podia dizer-se com verdade, embora não sem ironia, que essa reentrada no mundo da Idade Média portuguesa, agora de forma mais focalizada, aconteceu num Congresso, mais um congresso sobre momentos fundadores na Península Ibérica, onde o destino o voltaria a reunir com José Mattoso, com quem se relacionava já há muito. 0 famoso Congresso de Guimarães celebrado em 1996 foi um mega-congresso sobre o nascimento da nacionalidade, desta vez sob o signo de Afonso Henriques. Peter Linehan participou com uma comunicação sobre a coroação, ou melhor, sobre a não-coroação dos reis de Portugal, com uma tese que se opunha às teorias de José Mattoso sobre a mesma temática. Apesar de discordar de Mattoso naquele ponto, Linehan nutria por ele um respeito tão profundo que lhe enviou a comunicação antes de a apresentar publicamente, para saber o que ele achava e para lhe dar parte do que ia dizer. Quando se encontraram nesse Outubro de 1996, Mattoso disse-lhe, com a qualidade de um investigador a sério e com um ar quase divertido "Rendo-me aos seus argumentos!". As boas relações entre os dois nunca azedaram, pelo contrário, mas a verdade é que a questão da coroação e unção dos reis portugueses daria azo a uma das polémicas mais interessantes de estudar e mais profícuas da nossa historiografia, exemplar pela lisura de estilo e trato entre dois historiadores que se estimavam muito, embora discordassem sobre alguns tópicos importantes. 0 debate, que deu origem a mais dois artigos de cada um dos dois, acabaria com uma vitória para Linehan, pelo menos por então. Mas para quem assistiu a esse debate a seriedade, a erudição e a elegância dos argumentos então esgrimidos foram um exemplo do que um debate académico deve ser. Não era a primeira vez que se debruçava sobre questões relevantes para a nossa historiografia, mas o artigo "Religion, nationalism and national identity in medieval Spain and Portugal" (1982) tinha passado muito mais desapercebido.

Vinha a Portugal também para ir à Torre do Tombo procurar um selo de João de Abbeville, cujo percurso estava a retraçar nessa altura, como ele próprio conta nas suas palavras. Não encontrou o selo de João de Abbeville, mas deparou-se com 
documentação pontifícia original e riquíssima, bem como um conjunto de outra documentação (nomeadamente de carácter jurídico) que lhe aguçou a curiosidade e a vontade de regressar ao arquivo, desta vez aos arquivos portugueses, e retomar o que fizera apenas parcialmente aquando da pesquisa para a sua tese de doutoramento.

Ao abrigo de um projecto financiado pela British Academy fez várias estadias de investigação em Portugal, que tive a sorte de poder acompanhar de perto, pois coincidiram, em alguns casos, com as minhas próprias visitas a esses arquivos, durante o levantamento documental que fazia para a minha tese sobre o papel dos eclesiásticos na construção do poder régio em Portugal nos séculos XII e XIII.

Acompanhar o Peter Linehan nas suas visitas aos arquivos foi um privilégio. Na Torre do Tombo, onde passou mais tempo, Lips e Legs, Nun e Hairdresser, os carinhosos nomes de código que deu aos eficientes funcionários da sala de leitura da Torre do Tombo, traziam-lhe, de forma muito diligente, toda a documentação que pedia, só parecendo inquietar-se um pouco quando aquele investigador inglês colocava o casaco pela cabeça e parecia mergulhar nos documentos, que ficavam completamente invisíveis para os outros. O Peter tinha uma luz ultravioleta de bolso que funcionava a pilhas, mas precisava de escuridão para funcionar bem, daí o aparato de tentar fazer uma câmara escura com o casaco para poder melhor aproveitar do efeito dos ultravioletas. Aparte estes detalhes, dos quais seguramente muitos dos então leitores da Torre do Tombo se lembram, pude também verificar em pessoa o seu método, o seu rigor, a forma como trabalhava cada documento, com uma atenção aturada a todos os aspectos possíveis, desde a proveniência, produção, marcas marginais, sinais de validação, formato, dimensão, notas contemporâneas e anotações posteriores, até aos aspectos de conteúdo, sem falhar os detalhes sobre os processos e agentes de escrita, testemunhas e confirmantes, sinais, selos... e tudo isso trabalhando a uma velocidade estonteante.

Aprendi muito, como todos com quem Peter Linehan convivia, sobre os detalhes mais relevantes e ínfimos dos diversos tipos de documentação, sobre o olhar crítico que temos de ter e sobre o papel dos nossos olhos e intelecto na construção do edifício historiográfico que cada um de nós acaba por construir.

Para além dos debates académicos, o investigador que havia nele nunca perdia o seu lado de professor. Muito atento à investigação de cada um, dedicava uma atenção especial aos mais jovens, a quem sempre incentivava de forma positiva e concreta, "perdendo tempo" com excertos de leitura difícil ou trechos de latim mais obscuros, procurando sempre o sentido profundo do que a documentação poderia fornecer, entusiasmando-se com as descobertas alheias e ensinando tudo o que sabia com a sua proverbial generosidade para com aqueles cujo trabalho ele respeitava. O Peter gostava que pensassem nele como num historiador antiquado, apenas porque achava que no mundo actual, no qual se dá tanta atenção às "metodologias" e às "modas historiográficas" - duas áreas que ele também dominava com à-vontade - os historiadores se deixam seduzir com demasiada frequência pelo facilitismo das visões apriorísticas e anacrónicas. Para ele, o que distinguia um historiador "a sério" dos restantes era a capacidade heurística, o trabalho com e sobre a documentação, o rigor crítico e a capacidade de construir um edifício historiográfico a partir das bases documentais, sem esperar nada da documentação, mas sabendo retirar dela tudo aquilo que ela tem para dar.

38 O resultado final desse trabalho de arquivo acabaria por se consumar nos volumes de Portugalia Pontificia, Materials for the History of Portugal and the Papacy (1198-1417), que 
seriam dados à estampa em 2013, e no seu último livro, At the Edge of the Reformation: Iberia before the Black Death (2019) que ainda é subsidiário dessa profunda e exaustiva investigação.

Mas entre 1996-1997, quando retomou a sua investigação sobre temas portugueses e a pesquisa documental nos arquivos portugueses, e a edição do seu último livro sobre Portugal em 2019, muita da sua produção se centrou sobre temas que direta ou indiretamente se ligavam com questões fundamentais para os medievalistas portugueses.

A legacia do cardeal João de Abbeville, atrás de cujo selo entrara na Torre do Tombo, deu origem a uma reconstituição notável do percurso de vida desse homem tão pouco comum e com tantas ligações a Portugal, num artigo que só viu a luz do dia em 2001, “A papal legation and its aftermath: Cardinal John of Abbeville in Spain and Portugal, 1228-1229".

41 Mas o seu percurso nesse mundo começara mais cedo. Logo em 1997, num artigo muito mal conhecido mas premonitório do que o seu trabalho com a cultura jurídica em Portugal iria ser. "Two marriage cases from thirtheenth century Iberia" levantava a questão do envolvimento relevante dos bispos de Lisboa em casos de divórcio.

$42 \mathrm{Na}$ verdade, nesse mesmo ano, o texto das Senhoras de Zamora também nos fornecia muitos dados para o papel de destaque e central no mundo dos Dominicanos hispânicos e no mundo das negociações com Roma onde também surgia o provincial dos Dominicanos, esse Soeiro Gomes responsável pelos decretos laicales que tanto tinham enfurecido Afonso II de Portugal em 1221, cujo percurso a historiografia portuguesa tem injustamente negligenciado e que nos confronta de forma marcante com a circulação peninsular e extra-peninsular destes eclesiásticos cuja esfera de influência em muito extravasava a expectável Península. É quando trata dos dominicanos de Zamora que Linehan detecta os sinais de uma cultura jurídica apurada e refinada, que o seu trabalho no arquivo dessa cidade, combinado com a sua investigação nos arquivos de Braga, Porto e Coimbra, acabaria por confirmar e aprofundar.

43 A cultura jurídica dos cónegos de Zamora, que tantas e tantas vezes apareciam como juízes delegados nos casos portugueses que eu mesma levantara, foi tratada com mestria em artigos em nome individual - "An impugned chirograph and the juristic culture of early thirteenth-century Zamora" (2006); "El cardenal zamorano D. Gil Torres y la sociedad zamorana de su época" (2007); "Columpna firmissima: D. Gil Torres, the Zamoran cardinal" (2008) - e num livrinho em colaboração com Carlos Lera, Las postrimerias de um obispo alfonsino. Don Suero Pérez, el de Zamora (2003).

Os processos portugueses que analisou sobre Lorvão deram mais tarde origem a um interessante e também muito pouco conhecido processo, que publicou em conjunto com Martin Bertram num artigo em homenagem a Domenico Maffei, "The Law's Delays: Two Chapters in the Thirteenth-Century History of S. Maria de Lorvão (by Peter Linehan); Mit Bemerkungen zu einer Extravagante Gregors IX. (von Martin Bertram)" (2014), onde aquilo que ele gostava de chamar as "maquinações da Lei" são por demais evidentes.

O multifacetado legado que nos deixa é imenso. Muito embora o seu trabalho se tenha centrado sobretudo em Leão e Castela, e numa fase posterior em Portugal, a verdade é que as análises que faz, a forma quase holística como trata os problemas que estuda, o brilho das suas intuições, são de interesse global para todos os estudiosos da Idade 
Média e seus contornos difíceis de apreender. Quase podemos suspirar de alívio ao pensar que, detestando embora as tais "historical conferences" com tanta veemência, não tenha resistido à tentação de participar em tantas e de converter os seus primeiros esboços em artigos, por vezes livros com os quais nos brindou.

Este inglês que dedicou a sua vida ao estudo da Península Ibérica e que acaba de nos deixar fisicamente, vai ainda continuar a acompanhar-nos nas nossas estantes por muitos anos, como obra de consulta obrigatória e de estudo apurado. $V$ Semana de Estudos Medievais organizada pela Faculdade de Letras da Universidade do Porto em 2005. Convidado para a conferência inaugural intitulada Acta et Agenda, impressionou-me a desenvoltura com a qual tratou de alguns aspetos das relações entre as monarquias castelhanas e portuguesa com o Papado no século XIII e, sobretudo, retive a apresentação que fez do projeto que tinha em mãos, já nessa altura: o da inventariação da documentação pontifícia referente a Portugal entre 1198 e 1417.

Essa apresentação correspondia à ideia que eu tinha do Prof. Peter Linehan. Como acontece muitas vezes com os jovens investigadores, eu "conhecia" o autor somente através da sua obra. Com efeito, por esses tempos, já tinha lido a sua tese de doutoramento, na versão publicada em 1971 sob o título The Spanish Church and the Papacy in the Thirteenth Century, assim como os artigos que tinha dedicado às queixas do episcopado castelhano nos anos 1260 , os quais me ajudaram a perceber melhor os gravamina que, pela mesma altura, os bispos portugueses apresentavam na Cúria romana contra o rei Afonso III.

51 O meu Peter Linehan não era tanto na altura - nem ainda é hoje - o cronista de um mosteiro feminino de Zamora ou o analista inteligente da historiografia medieval castelhana, mais sim, e sobretudo, o conferencista que vi em 2005, o especialista das relações entre o papado e os reinos ibéricos nos séculos XIII e XIV. Sendo este o filão da sua obra sobre a qual tenho trabalhado e aprendido ao longo desta última década e meia, é, pois, sobre esta área específica da sua produção científica que eu gostaria de deixar o meu testemunho.

Não é surpresa para ninguém que as ligações entre os reinos de Leão e Castela (menos Aragão e Navarra) e o Papado constituíram um dos fios condutores do seu trabalho de historiador ao longo das quase cinco décadas de investigação. Não é possível - nem faz muito sentido neste curto testemunho - proceder a uma análise fina da sua produção nesta área, nem tão pouco, escalpelizar os seus impactos sobre a medievalística ibérica. Ainda assim...

53 O trabalho de Peter Linehan nesta temática é o espelho da sua vontade em não ficar prisioneiro de um tipo específico de História, nem de uma cronologia precisa, apesar do seu trabalho se ter centrado em grande medida no século XIII e primeira metade da centúria seguinte (com incursões pontuais para os períodos anteriores ao séc. XII e para o século XV). Autor que se sentia à vontade com a redação de grandes sínteses - como testemunha a sua tese -, creio que gostava sobretudo de reconstituir os meandros da estória/História através de acontecimentos ou de documentos específicos. Para ele, o essencial era o documento e as pistas que este último encerrava para a compreensão das ações das personagens históricas. E ele foi um investigador que tinha as 
competências e qualidades para "ler" documentos medievais, sobretudo aqueles de particularmente difícil descodificação, como é o caso da documentação latina emitida pelas chancelarias pontifícia ou episcopais. Peter Linehan tinha, indubitavelmente, uma intuição "heurística" ímpar, que lhe permitia mobilizar a informação contida em documentos insuspeitos para as suas análises históricas. Acresciam a esta perspicácia, o gosto, a paciência e o domínio que tinha da paleografia e diplomática pontifícias, como os profundos conhecimentos de direito canónico, que lhe permitiam analisar - e publicar - com mestria intricados documentos ligados com a Sé apostólica ou a retirar argumentos credíveis nas variantes encontradas no cotejo de diversos exemplares de um mesmo documento. Para dar uma dimensão do seu labor (beneditino?) de editor, veja-se, como exemplo, a inquirição realizada no âmbito de um processo entre a Sé de Coimbra e o mosteiro de Santa Cruz, publicada em dois exemplares no segundo volume dos Portugalia Pontificia, que lhe ocupou a dupla coluna a soma de 104 páginas!

Esta última obra constitui aliás um marco do trabalho de Peter Linehan sobre as relações ibero-pontifícias, como veremos. Importa sublinhar que este último sofreu uma evolução ao longo do tempo, resultante dos diferentes projetos de investigação pessoais abraçados ao longo da sua carreira. Esta evolução encontra-se bem patente nas quatro coletâneas dos seus trabalhos - que parecem "resumir" bem a sua obra publicados pela Variorum com uma cadência pendular a cada dez anos.

Não é possível saber se a elaboração da tese de doutoramento, publicada em 1971, "secou" na década seguinte o seu entusiasmo pela questão específica das relações entre o papado e os reinos de Castela e de Portugal. De facto, a sua produção nesse âmbito, justamente para esse período, parece algo limitada, como atesta o facto da sua primeira coletânea Spanish Church and Society, 1130-1300 (1983, Variorum collected studies series, $\mathrm{n}^{\circ} 184$ ) publicar somente dois trabalhos sobre os agravos da Igreja castelhana discutidos na Cúria apostólica.

Peter Linehan continuou a publicar artigos baseados em documentação apostólica ao longo da década de 80. Capitalizando certamente o levantamento heurístico feito para sua tese, assim como as várias incursões efetuadas nesses anos a diversos arquivos ibéricos, aprofundou durante essa época o estudo das marcas de chancelaria da documentação pontifícia enviada ao reino castelhano. Pôde, dessa forma, desenvolver um trabalho fundamental de identificação dos procuradores castelhanos ou que defendiam interesses castelhanos na Cúria pontifícia no século XIII. Interessou-se igualmente por letras apostólicas sem selo e o seu domínio da documentação apostólica permitiu-lhe mobilizar as fontes fiscais conservadas pela Câmara Apostólica para estudar a missão de um coletor em Castela nos inícios do século XIV, todos trabalhos publicados na sua segunda coletânea Past and Present in Medieval Spain (1992, Variorum collected studies series, $\mathrm{n}^{\circ}$ 384).

O desenvolvimento do projeto de inventariação dos diplomas apostólicos e outros legal wrangles relativos a Portugal, na década de 1990, levou-o a deslocar os seus interesses de investigação para a zona mais ocidental da Península. Contudo, ele não deixou de se manter fiel à prática de exumar pergaminhos dos arquivos eclesiásticos castelhanos, na maior parte dos casos de difícil acesso, com os quais produziu artigos particularmente relevantes... para o estudo dos meandros curiais do final do século XIII. O resultado do seu trabalho de autêntico detetive - uma vez que lhe interessava sobretudo perspetivar as razões que levaram à conservação, nos referidos arquivos, de documentos que aparentemente em nada se relacionavam com assuntos ibéricos - encontra-se patente 
na sua terceira coletânea intitulada significativamente The Processes of Politics and the Rule of Law: Studies on the Iberian Kingdoms and Papal Rome in the Middle Ages (2002, Variorum collected studies series, $\mathrm{n}^{\mathrm{0}}$ 741).

A sua quarta e última coletânea, Historical Memory and clerical activity in medieval Spain in Portugal (2012, Variorum collected studies series, $\mathrm{n}^{\circ}$ 1011), publicada uma década mais tarde, acentuou o trabalho do período anterior em termos de estudos sobre a diplomacia e a diplomática pontifícias em inícios do século XIV, sem contar os trabalhos fundamentais sobre as redes de relações dos cardeais castelhanos no século XIII ou mesmo a legação de João Abbeville na Península (à conta da qual Peter Linehan tinha entrado pela primeira vez na Torre do Tombo em 1997).

O trabalho heurístico por detrás de muitos dos textos publicados ao longo de décadas viria a plasmar-se, em 2013, na publicação em dois volumes, pela Fundação Calouste Gulbenkian, do tão aguardado inventário e estudo (já apresentado em 2005) com o título Portugalia Pontificia: materials for the history of Portugal and the Papacy, 1198-1417. Agora, definitivamente, o autor colocava no centro das suas atenções o "caso" português, que ela abordara a espaços nos seus trabalhos anteriores. Desde a sua publicação, os Portugalia Pontificia tornaram-se uma obra de referência imprescindível, não somente pelos 1427 documentos aí sumariados e os 185 diplomas publicados em 843 páginas, mas também pela sua robusta introdução, que lhe permitiu passar em revista vários aspetos das relações entre a Monarquia e a Igreja portuguesas nos tempos dos reis D. Afonso III e D. Dinis. Sem esquecer o levantamento minucioso das marcas de chancelaria da documentação então sumariada, com as quais identificou os procuradores na Cúria ligados a interesses portugueses, o que lhe permitiu constatar, simultaneamente, a existência de uma autêntica cultura de litigação por parte dos clérigos lusos de Duzentos e Trezentos.

Este projeto acabou por ser fundamental na elaboração da sua última obra. At the Edge of Reformation. Iberia before the Black Death (2019) representa de facto um retorno à "reforma" e ao relacionamento Monarquia-Igreja abordados na sua tese de doutoramento. Mas, desta feita, em vez de perscrutar a luta pelas liberdades eclesiásticas que havia marcado esse relacionamento ao longo das décadas centrais do século XIII, Peter Linehan procurou historiar as relações entre o papado e os reinos de Castela e Portugal durante a primeira metade do século XIV. Com pontes evidentes com a realidade ibérica ducentista que ele tão bem conhecia, este livro procura detetar e explicar a estratégia seguida pelos reis portugueses e castelhanos desse período, com vista ao domínio dos respetivos episcopados, em grande medida com a ajuda de legistas pertencentes às respetivas cortes régias. As evidências sobre a semelhança das estratégias seguidas então pelas duas monarquias são colhidas, em grande medida, numa documentação apostólica utilizada de forma maciça e não raras vezes com o recurso à transcrição em nota, sobretudo em termos das letras secretas dos papas Clemente V a Clemente VI, uma tipologia documental reservada pela chancelaria apostólica para a troca de correspondência de natureza diplomática entre o papado e os reis, cortes e clérigos da Cristandade. $O$ recurso frequente a esta documentação, inclusivamente a transcrição dos passos mais significativos, tem um valor que ultrapassa a mera prova das suas aceções. Com efeito, Peter Linehan não ignorava que esta documentação se encontra parcialmente inédita, pelo que a sua mobilização para o estudo do caso português permitiu ao autor divulgar e disponibilizar informações até 
então desconhecidas sobre as relações entre Portugal e a Cúria apostólica no tempo do papa João XXII (1316-1334).

61 Foi no âmbito deste avanço mais demorado de Peter Linehan pelo século XIV que os nossos caminhos se cruzaram, uma vez que também eu trabalhava tais temáticas. Contudo, não se tratou de uma partilha igualitária, pois do diálogo, das trocas de ideias e de referências de documentos, "transacionados" quase como cromos de coleção, acabei por ser eu o mais beneficiado. De facto, foi ele que me chamou a atenção para a existência de umas letras apostólicas em que o rei Afonso IV de Portugal solicitava ao papa a nomeação de um cardeal português. Sempre achara estranho que a realeza portuguesa não se tivesse embrenhado numa tal estratégia na primeira metade do século XIV, quando a mesma foi claramente evidente, à época, no caso das monarquias inglesa, aragonesa e castelhana. Peter Linehan não se limitou a informar-me dessa referência, pois rapidamente chegaram às minhas mãos as fotocópias desse e de outros documentos que me interessavam dos registos apostólicos desse mesmo João XXII.

Este gesto resume bem a sua legendária generosidade. Porventura mais do que a sua produção científica, os documentos que pacientemente analisou e deu a conhecer, a sua visão da história e dos historiadores ibéricos medievais, guardo para mim o investigador rigoroso, paciente e generoso, que certamente retirava grande prazer da troca de ideias e da orientação dos investigadores mais novos pelos intrincados meandros da Cúria romana e das cortes eclesiásticas ibéricas dos séculos XIII e XIV. estima por Peter Linehan ao contribuir, modestamente, para tornar mais acessível uma parte da sua obra, traduzindo-a e indexando-a. Esse privilégio foi também para mim uma forma, decerto imperfeita e insuficiente, de retribuir os incontáveis actos de generosidade, encorajamento e afecto que ele me prodigalizou ao longo de mais de doze anos. É-me difícil, e seria sem dúvida despropositado, explicar o que significou para mim, aos vinte e poucos anos e intelectualmente à deriva, travar conhecimento com uma personalidade tão subtil, cativante e inspiradora como era a dele, tal como me é difícil separar mentalmente o diálogo sobre a história, a historiografia, a literatura, Inglaterra, Espanha, Portugal, que mantivemos ao longo dos anos, do processo íntimo e lento através do qual a afinidade de ideias e a discussão de interesses comuns se dilui na amizade. Pensar e escrever sobre a tradução e a indexação, dois elementos acessórios da actividade literária, mas que ocuparam uma parte importante da minha relação com Peter Linehan, permite-me, de certa forma, arrumar a memória, estruturar imagens e impressões e reflectir, discretamente, sobre algumas facetas da sua obra, do seu método e da sua maneira de pensar.

Deixo assim propositadamente de lado os grandes temas em torno dos quais Peter Linehan construiu uma obra historiográfica indispensável, singular e 
extraordinariamente coerente: a articulação política, institucional e económica entre a Igreja peninsular, o papado e as monarquias ibéricas; a reforma eclesiástica e a sua precária implantação peninsular; os interesses socioeconómicos e as inclinações morais do clero medieval; os conflitos de jurisdição entre instituições eclesiásticas e entre estas e a sociedade laica; a relação entre história, historiografia e construção ideológica do passado, para mencionar apenas os principais. Prefiro considerar aqui a inteligência e a sensibilidade particulares com que estes temas foram trabalhados, e que a leitura esquadrinhadora, rente ao texto, própria da tradução e da indexação ajudam, creio eu, a descortinar.

O meu ponto de partida é um livro insólito e fascinante publicado em 1870 e intitulado Brewer's Dictionary of Phrase and Fable. Foi este o livro que Peter Linehan, insinuando como era seu hábito um caminho a seguir que se me afigurava então perfeitamente nebuloso, me recomendou que tivesse à mão ao traduzir The Ladies of Zamora (1997) e que utilizasse para deslindar a contextura da sua prosa. Porquê começar por aqui? Mais próximo do gabinete de curiosidades que de uma enciclopédia, o Brewer's é um fourretout de anotações e micro-biografias histórico-literárias, de provérbios e expressões vernaculares, de mitos e anedotas, de máximas latinas, epigramas, versos, frases e ditos memoráveis, que pretendem representar o universo literário de um inglês culto da época vitoriana. Esta erudição omnívora e idiossincrática pressupõe a ideia que a comunicação inteligente se constrói a partir de um fundo comum de referências culturais, susceptível de ser actualizado (a revisão mais recente do Brewer's data de 2018) mas essencialmente estável. O carácter analógico e idiomático da escrita de Peter Linehan - donde provém boa parte do seu sabor particular e das dores de cabeça de quem se propõe traduzi-la - explora precisamente esses espaços linguísticos e literários que o Brewer's cartografa, sem chegar a esgotar, servindo-se da expressividade do inglês falado, das especificidades culturais e académicas britânicas (a vida colegial de Oxbridge presta-se a luminosos paralelos com a vida eclesiástica na Idade Média) e da alusão a obras e autores "canónicos" - de Dickens a Byron, de Shakespeare a Cervantes, de Milton a Austen - para ilustrar um argumento ou para introduzir uma perspectiva histórica diferente. Apurada por uma disposição para o peculiar e um olhar nato de miniaturista, a qualidade literária da prosa de Peter Linehan transparece com especial vivacidade sempre que é posta ao serviço da caracterização das motivações e interesses do ser humano e da explicação das forças e circunstâncias que os determinam. A fórmula lapidar, a adjectivação opulenta e colorida e o gosto do paradoxo (aos quais voltarei mais à frente), a capacidade para captar e exprimir o lado absurdo, cómico ou grotesco de uma situação ou personagem, fazem emergir, nas páginas de The Ladies of Zamora como em tudo o que Peter Linehan escreveu, representações vibrantes e incisivas da freira leonesa em busca de prazer, do rei castelhano em busca de poder, do arcebispo toledano em busca de privilégios, do papa avinhonês em busca de influência, do pregador francês em busca de salvação.

Este talento de fisionomista é aplicado com admirável efeito à análise histórica. Se ela se molda com naturalidade à forma narrativa, a sensibilidade histórica de Peter Linehan é, a meu ver, essencialmente analítica e distingue-se em particular pela capacidade de reconstituir e de explicar o encontro entre os indivíduos e as estruturas e processos que organizam a época em que eles vivem - sejam eles a reforma da Igreja, a expansão das ordens mendicantes, o processo romano-canónico, o desenvolvimento da administração régia, a doutrina canónica do matrimónio ou a elaboração da escolástica. A obra historiográfica de Peter Linehan pulula de gente, de homens e mulheres agindo 
a título próprio ou em nome das instituições a que pertencem, desde o rei e o bispo até ao mais obscuro Petrus Martini ou Dominicus Johannis, passando pelo cónego ou corregedor de cuja existência subsistem apenas os vestígios de três ou quatro documentos. Esta fauna pletórica e as incontáveis relações que a animam são o seu objecto de análise primordial. Quando penso da maneira como Peter Linehan aborda o passado e o reconstitui, vêm-me imediatamente ao espírito a lucidez, a paciência e a intuição com que ele restaura, esclarece e associa os laços visíveis e invisíveis que há sete ou oito séculos ligaram um mestre-escola em Coimbra a um auditor em Roma, um rei em Aragão a um procurador em Avinhão, um civilista bolonhês a uma contenda bracarense, um Mestre-Geral dominicano a uma bacanal conventual em Zamora. Nos últimos dez anos, em vez de se deixar tentar por uma síntese que não o estimulava $\mathrm{e}$ para a qual não se sentia talhado, Peter Linehan dedicou-se a despinçar da documentação os fios ténues da trama histórica que se tece no dorso dos rescritos papais, onde estão rabiscados, entre outras menções de chancelaria, os nomes dos procuradores curiais que os obtiveram e dos escrivães, taxatores e distributores que os produziram: uma discreta linguagem do poder (a expressão é de Olivier Canteaut) que Peter Linehan sondou com subtileza através da sua obra e que restituiu enfim, de forma sistemática, em Portugalia Pontificia: Materials for the History of Portugal and the Papacy 1198-1417 (2012) e na derradeira obra, actualmente no prelo, que será publicada sob o seu nome: España Pontificia: Original Papal Letters to Spain 1198-1303.

À semelhança do Index Actorum Romanorum Pontificum, estas duas compilações recenseiam (e, no caso de Portugalia Pontificia, publicam parcialmente) a documentação papal conservada nos arquivos portugueses e espanhóis, segundo o modelo de levantamento proposto em 1953 por Franco Bartoloni para suprir as lacunas dos registos papais, os quais conservam, como se sabe, apenas uma parte dos documentos produzidos pela chancelaria pontifícia. Parece-me supérfluo sublinhar a relevância para a historiografia portuguesa de Portugalia Pontificia, uma obra que merece figurar ao lado de Papsturkunden in Portugal, Monumenta Henricina e Documentos Medievais Portugueses como um dos grandes monumentos de heurística e de erudição do medievismo português desde Alexandre Herculano. Foi ao elaborar os índices de Portugalia Pontificia e, anos mais tarde, de España Pontificia que me apercebi verdadeiramente - para não dizer fisicamente - da excepcional abundância de matéria histórica que Peter Linehan resgatou ao longo dos anos à poeira silenciosa dos maços e carpetas e à custódia possessiva dos cónegos-arquivistas. As centenas de nomes próprios, topónimos, dignidades, ofícios, igrejas, catedrais, capelas e mosteiros que enchem as mais de cem páginas do índice de Portugalia Pontificia (deixo de parte o de España Pontificia, que está ainda por publicar) representam um concentrado impressionante dessa matéria histórica. Mas são mais do que isso. Tal como Peter Linehan o concebia, um índice deve ser mais que a soma das suas entradas: um índice deve reflectir as conexões e as solidariedades reveladas pela obra e oferecer ao leitor que as ignora diversas portas de entrada para poder aceder-lhes. Tanto quanto possível, as entradas são sistematicamente organizadas em arborescências, em agrupamentos que reflectem a arquitectura institucional que emerge das fontes, e ligadas entre si por remissões que reproduzem as ramificações da vida social e política. Assim, é possível obter pelo simples exame do índice uma noção precisa da composição de um cabido ou de um mosteiro, das relações e tensões de um e de outro com o resto da sociedade, do percurso individual dos seus membros. As datas-extremas permitem abarcar, num olhar, a existência documental dos indivíduos e das instituições, as ascensões e os 
declínios, os tempos fortes e fracos. Realizado nestes moldes, o índice de Portugalia Pontificia não se limita a condensar e a sistematizar a enorme riqueza de informação aí contida, mas tenta reconstituir, na sua expressão elementar, a qualidade dinâmica e relacional dessa informação. Este duplo exercício de compilação e de associação revelou-me, com um imediatismo e uma limpidez que a superfície polida do discurso historiográfico por vezes encobre, o assombroso volume da massa documental que alimenta a erudição de Peter Linehan e a delicada complexidade do trabalho de reconstituição das interacções entre indivíduos, instituições e ideias, para o qual tende a sua sensibilidade histórica.

70 As interacções institucionais dos indivíduos que habitam a obra de Peter Linehan envolvem, na sua grande maioria, a Igreja e a monarquia. $O$ contacto entre as motivações pessoais e as expectativas, procedimentos e solenidades inerentes à realidade institucional é altamente problemático e a sua análise presta-se a um modo de apreciação que constitui uma das características mais salientes e memoráveis da expressão literária de Peter Linehan: a ironia. As qualidades que fazem de Peter Linehan um ironista puro, à imagem de um Gibbon ou de um Trevor-Roper, são indissociáveis de uma percepção aguda da distância que separa o geral do particular, a regra da excepção, o indivíduo da instituição. No espaço que os separa cabem inúmeros contrastes e asperezas que uma análise generalizadora tenderia a descartar como ruído ou mera distracção, mas que o distanciamento irónico faz sobressair, dando ênfase à singularidade, à complexidade e à contingência das relações sociais e dos processos históricos. Peter Linehan alcança este efeito com extraordinária mestria, recorrendo com brio e discernimento ora à adjectivação antinómica, ora à perífrase, ora ao registo nobre para descrever situações escabrosas, cómicas ou rocambolescas. 0 distanciamento irónico concede-lhe ainda uma liberdade suplementar para especular, para formular conjecturas, para insinuar ao leitor certa possibilidade ou alternativa, sem exceder os limites da verosimilhança ou forçar as exigências da erudição. De resto, o mesmo expediente que lhe permite pintar em tons crus as fraquezas de um frade ou os paradoxos de um rei produz excelentes resultados quando Peter Linehan o utiliza para castigar os pecados capitais dos seus colegas de profissão: o modismo acrítico, a facilidade, a falta de audácia e de curiosidade, as querelas estéreis - jamais o erro inteligente, os excessos de erudição, a seriedade intelectual.

71 Peter Linehan partilhava com prazer as suas peripécias arquivísticas e os azares e circunstâncias que o desviaram do seu interesse primitivo pela Espanha dos anos 30 e o conduziram ao estudo da Espanha medieval. Estes dois aspectos do seu percurso intelectual e pessoal - a inclinação contemporânea do seu hispanismo e a descoberta da Espanha franquista dos anos 60 ao mesmo tempo que os seus arquivos - afiguram-seme inseparáveis da maneira como ele representava a história medieval peninsular, num diálogo complexo entre passado e presente, história e historiografia, ficção e realidade. Ao ler a sua obra, sobrevém-me frequentemente a impressão que cada argumento, cada capítulo, cada análise, encaixa num todo, numa concepção coerente da história ibérica em geral e da história espanhola em particular, que a contiguidade e a complementaridade das questões que servem de objecto a esses argumentos, capítulos e análises não explicam inteiramente. Duas outras razões contribuem, penso eu, para criar essa impressão de unidade conceptual. A primeira é uma coerência de tom e de perspectiva, resultante do distanciamento irónico que Peter Linehan aplica com igual liberalidade às fontes e aos seus comentadores e que se traduz numa abordagem historiográfica orientada para a complexidade e para a crítica e, inversamente, avessa a 
conclusões peremptórias, à síntese e ao dogmatismo. A segunda é uma coerência de método, que se caracteriza em particular pelo lugar privilegiado da heurística na obra de Peter Linehan. Raros são sem dúvida os medievistas para os quais a experiência humana e intelectual do arquivo terá sido mais estimulante como princípio da crítica e da imaginação históricas. A exploração documental dos fundos eclesiásticos espanhóis (e mais tarde portugueses) à qual Peter Linehan se lançou aos vinte e poucos anos, e que haveria de ocupar o resto da sua carreira académica, conduziu-o da sala de leitura do Archivo Histórico Nacional de Madrid - onde os documentos eram distribuídos (de mau grado) por dois ex-legionários fumadores de Ideales, que Peter Linehan e o seu camarada Richard Fletcher alcunharam de Chaos e Old Night (personificações do abismo que separa, no Paraíso Perdido de Milton, o céu da terra) - aos principais arquivos catedralícios e bibliotecas capitulares do país, de Barcelona a Zamora, de Toledo a Compostela, de Tarragona a Seo de Urgel. As investigações sobre a Igreja peninsular medieval - plenas de imprevistos, de façanhas diplomáticas face à indiferença dos cónegos-arquivistas, de novas (e duradouras) amizades e de um breve interrogatório pela policía de seguridad - foram ao mesmo tempo uma viagem através da Espanha, e Peter Linehan um observador tão receptivo, culto e perspicaz quanto o seu predecessor Richard Ford, autor do maravilhoso Hand-book for Travellers in Spain (1845).

Para um inglês recém-saído de Cambridge, esta peregrinação arquivística pelo país de Cervantes, onde trinta anos antes se travara uma guerra civil que ele estudara através da obra clássica de Hugh Thomas e que fora a semente do seu interesse pela história espanhola, não foi por certo avara em exotismo picaresco, mesmo se à força de desarrollismo a Espanha franquista se tornava cada vez menos diferente e cada vez mais distante dos estereótipos casticistas. Ainda assim, a reminiscência da vendedora de abajures feitos com o pergaminho arrancado aos fólios de um antifonário medieval, que ele cruzou numa praça de Barcelona em 1966, ou da menção dos pesetas aposta ao dorso de certos documentos papais do Archivo Histórico Nacional - testemunhos ambos de um comércio peculiar e longínquos resquícios, talvez, da desamortização de Mendizábal ou das invasões napoleónicas - não deixou certamente de estimular o seu sentido de humor e a sua imaginação. Da sua peregrinação arquivística o estudante frustrado da Espanha contemporânea não tirou somente anedotas e transcrições de letras papais, mas uma concepção das relações entre a Igreja e as monarquias ibéricas na Idade Média como elemento estruturante da construção política e ideológica da Espanha moderna, e uma aptidão particular para examinar o passado medieval peninsular numa perspectiva bifocal, com um olho na Idade Média e o outro na sua reconstituição historiográfica, na sua representação simbólica e ideológica e nas vicissitudes da sua sobrevivência documental. $\mathrm{Na}$ análise histórica de Peter Linehan, acontecimentos como a batalha de Las Navas ou processos longos como a subordinação política e económica da Igreja castelhana aos interesses do poder régio ou a relação entre a expansão deste último e a exacerbação das tendências concubinárias e mundanas do clero hispânico na primeira metade do século XIV - para dar apenas alguns exemplos - inscrevem-se num panorama interpretativo erudito e multiforme, que alterna a Espanha visigoda e a Espanha filipina, a historiografia do século XIII e a historiografia do século XIX, Juan de Mariana e Menéndez Pelayo.

73 A obra de Peter Linehan, a cuja excepcional riqueza e inteligência se vem agora juntar infelizmente o atributo da fixidez, merece ser lida e discutida. Se os medievistas portugueses têm a sorte de poder fazê-lo enquanto dever profissional, os estudantes de história que aspirem a imitá-los encontrarão em tudo o que Peter Linehan escreveu o 
fruto complexo e inspirador de uma inteligência e de uma sensibilidade histórica singulares, expresso num estilo primoroso que é, por si só, uma forma de imersão cultural. Alegra-me imaginar os prazeres alheios do primeiro contacto com a sua obra, provavelmente através das páginas de The Ladies of Zamora: as primeiras gargalhadas solitárias, as primeiras dificuldades, as primeiras intuições. Como os trabalhadores na vinha, a obra de Peter Linehan recompensa com igual generosidade neófitos e aficionados. Para todos aqueles, enfim, que tiveram durante anos o privilégio da sua amizade e do seu desvelo, e que compreendem com pesar o muito que perderam, a sua obra resta um consolo tão insuficiente quanto precioso. Londres. Filho de um escriturário de corretagem e de uma professora, Peter Linehan fez a sua educação preparatória e secundária como bolseiro na St Benedict's School, em Ealing. Em 1961 entrou com uma bolsa no St John's College, em Cambridge, como estudante de licenciatura em História, e aí permaneceu durante toda a sua longa carreira académica. Eleito Research Fellow em 1966, Peter Linehan concluiu o seu doutoramento, sob a supervisão de Walter Ullmann, em 1969, com uma tese intitulada "Reform and Reaction: The Spanish Kingdoms and the Papacy in the Thirteenth Century". Esta tese, da qual resultou The Spanish Church and the Papacy in the Thirteenth Century (1971), a primeira monografia de Peter Linehan, foi distinguida pela Universidade de Cambridge com o Thirlwell Prize e a Seeley Medal de 1970-1971. Em 1969, Peter Linehan foi eleito Fellow \& Lecturer do St John's College, e entre as várias funções que aí desempenhou, ao longo de mais de cinquenta anos de estreita associação institucional, intelectual e afectiva, destacam-se as de Tutor (1977-1997), Dean of Discipline (1999-2010) e editor da história do college, publicada em 2011. Fellow da Royal Historical Society desde 1971, membro correspondente da Real Academia de la Historia de Madrid desde 1996 e fellow da British Academy desde 2002, Peter Linehan foi investido como doutor honoris causa pela Universidade Autónoma de Madrid em 2018.

Admirado e acarinhado por sucessivas gerações de amigos, colegas e estudantes, Peter Linehan faleceu no dia 9 de Julho de 2020, em Cambridge, aos 76 anos de idade. Sobrevivem-no a esposa Christine (née Callaghan), os seus três filhos, Gabriel, Frances e Sam, e os seus cinco netos, Oliver, Zachary, Max, Alba e Beatrice.

\section{NOTAS}

1. Um comentário semelhante, ouvido pela mesma altura, é relatado por Flávio Miranda: https:// faeehp.wordpress.com/2020/07/10/peter-linehan-1943-2020-e-o-legado-historiografico/ (consultado em 11 de Outubro de 2020).

2. Também Malcolm Schofield, citado na notícia necrológica publicada pelo St John's College, destaca a sua "legendary hospitality": https://www.joh.cam.ac.uk/incisively-intelligent-fellowst-johns-dies-aged-76 (consultado em 11 de Outubro de 2020). 
3. Este e outros títulos da sua vasta obra, citados ao longo deste texto, remetem para a bibliografia de Peter Linehan elaborada pelos autores deste artigo, disponível na secção "Recursos" da página web do IEM (https://iem.fcsh.unl.pt/imagens/files/ BIbliografia_Peter\%20Linehan.pdf). As datas remetem para o ano de edição, em função dos quais se encontra ordenada a bibliografia.

4. LINEHAN, Peter A. - Past and Present in Medieval Spain. Aldershot: Variorum, 1992 (sinopse).

5. A aspiração inicial de Peter Linehan a estudar a ascensão do franquismo foi rapidamente frustrada pelo contexto político a académico espanhol dos anos 60 , que o desviou para a Idade Média, mas o seu fascínio pelo século XX permaneceu.

6. E.g. LADERO QUESADA, Miguel Ángel - Medievalismo 4 (1994), pp. 335-345; Boletín de la Real Academia de la Historia 192 (1995), pp. 103-117; v. também BAUTISTA, Francisco - Hispania LXXIV (246) (2014), pp. 269-275, p. 274.

7. É o caso da recensão elogiosa, mas não acrítica de BRANCO, Maria João Violante - Lusitania Sacra 8-9 (1996-1997), pp. 739-744.

8. LINEHAN, Peter - History and the Historians of Medieval Spain. Oxford: Clarendon Press, 1993, p. 7.

9. Cf. GEARY, Patrick J. - The myth of nations: the medieval origins of Europe. Princeton:

Princeton University Press, 2002; WOOD, Ian N. - The modern origins of the early Middle Ages. Oxford: Oxford University Press, 2013.

10. LINEHAN, Peter; VALERO, Juan Miguel - "Peter Linehan on History and Europe, una entrevista". Pliegos de Yuste 7-9 (2008), pp. 6-8. Disponível em http://

www.pliegosdeyuste.eu/n78pliegos/pdf/n78p5.pdf (consultado em 11 de Outubro de 2020).

11. A tradução portuguesa, a cargo de André Vitória, foi publicada por uma pequena editora entretanto desaparecida (Fio da Palavra), cuja coordenação editorial na área da história esteve a meu cargo. Esta edição é complementada por um estudo dedicado a uma das figuras centrais do enredo, o bispo Suero Pérez de Zamora, que fora publicado em 2003.

12. LINEHAN, Peter - Spain, 1157-1300: A Partible Inheritance. Oxford: Wiley-Blackwell, 2011, p. 87.

13. CATLOS, Brian - Bulletin of Hispanic Studies 97 (2020), pp. 887-888.

14. LINEHAN, Peter; VALERO, Juan Miguel - "Peter Linehan on History and Europe, una entrevista", p. 6.

15. LINEHAN, Peter; VALERO, Juan Miguel - "Peter Linehan on History and Europe, una entrevista", ....

16. "the author seems so enraptured and immersed in the history he is recounting, and so unselfconsciously delighted by it, that he seems to forget his readers" (Bulletin of Hispanic Studies 97 (2020), p. 888).

17. LINEHAN, Peter; VALERO, Juan Miguel - "Peter Linehan on History and Europe, una entrevista", p. 6.

18. HENRY, James - A Small Boy and Others. 


\section{AUTORES}

\section{ANDRÉ EVANGELISTA MARQUES}

Universidade Nova de Lisboa, Faculdade de Ciências Sociais e Humanas. Instituto de Estudos Medievais. 1070-312 Lisboa, Portugal. andremarques@fcsh.unl.pt. https://orcid.org/ 0000-0001-8731-6355

\section{MARIA JOÃO BRANCO}

Universidade Nova de Lisboa, Faculdade de Ciências Sociais e Humanas. Instituto de Estudos Medievais. 1070-312 Lisboa, Portugal. mjbranco@fcsh.unl.pt. https://orcid.org/ 0000-0002-7165-5958

\section{MÁRIO FARELO}

Universidade Nova de Lisboa, Faculdade de Ciências Sociais e Humanas. Instituto de Estudos Medievais. 1070-312 Lisboa, Portugal. mario.farelo@fcsh.unl.pt. http://orcid.org/ 0000-0002-2905-6564

\section{ANDRÉ VITÓRIA}

Universidade Nova de Lisboa, Faculdade de Ciências Sociais e Humanas. Instituto de Estudos Medievais. 1070-312 Lisboa, Portugal. andrevitoria@fcsh.unl.pt. https://orcid.org/ 0000-0002-5804-5995 